\title{
Current and Emerging Treatment of Osteoporosis
}

\author{
Laura Tafaro and Nicola Napoli
}

\subsection{Introduction}

A fracture is a dramatic event for every patient because of pain, immobility and therefore the overall deterioration of their quality of life. Unfortunately, epidemiological data tell us that those who have suffered a fragility fracture are more at risk of suffering another in the same or other sites within a short time [1]. The goal of those treating a patient with recent fragility fracture should therefore not only be to treat the patient in the acute phase but also to prevent further fractures [2].

Interventions to increase bone mass to preventing further fragility fractures can be classified as pharmacological and non-pharmacological.

\subsection{Pharmacological Treatment for All Patients with Fragility Fractures}

Who are the patients that need pharmacological treatment? All European and international guidelines [3-5] do not base the need for treatment on the diagnosis of osteoporosis (based on the T-score) but on the risk of fracture, which is strongly influenced by the presence of a fragility fracture, especially vertebral or femoral fractures. A fragility fracture occurs spontaneously or following low-energy trauma in individuals with a low bone mineral density (BMD) [6].

This chapter is a component of Part 4: Pillar III.

For an explanation of the grouping of chapters in this book, please see Chapter: "The multidisciplinary approach to fragility fractures around the world-an overview".

\section{Tafaro $(\triangle)$}

Sant'Andrea Hospital, Sapienza University of Rome, Rome, Italy

e-mail: laura.tafaro@uniroma1.it

N. Napoli

Unit of Endocrinology and Diabetes, Campus Biomedico University of Rome, Rome, Italy

(C) The Author(s) 2021

P. Falaschi, D. Marsh (eds.), Orthogeriatrics, Practical Issues in Geriatrics, https://doi.org/10.1007/978-3-030-48126-1_15 
We do not need to apply an algorithm to decide who to treat because if our patient is a postmenopausal woman has had a fragility fracture, automatically we should consider her at high risk of further fractures. In the same way, an elderly patient with a hip fragility fracture should automatically be classified as having severe osteoporosis independently of other risk factors.

\subsubsection{Bedridden Fractured Patients}

Immobilisation itself causes osteopenia, indeed bedridden patients can suffer painful spontaneous fractures [7]. Secondary prevention trials usually do not include bedridden fractured patients, possibly because most common oral osteoporosis treatments are associated with esophagitis as a side effect and may increase the risk of reflux esophagitis for these patients [8]. However, a few studies on non-oral administration have shown good efficacy in patients with severe motor and intellectual disabilities [9]. Although further studies are needed, it seems to be important to treat this category of patients as well.

In conclusion, all orthogeriatric patients should start pharmacological treatment to strengthen their bone to prevent further fractures.

\subsubsection{Make a Diagnosis Before Treatment}

Before treatment it is important to make a differential diagnosis between primary and secondary osteoporosis because the anti-osteoporotic drug treatment would be useless if the main illness causing osteoporosis is not treated too.

In hospital, during the acute phase, it is important to investigate the osteoporosis to exclude secondary forms, by means of simple first-level blood tests (erythrocyte sedimentation rate, blood count, serum levels of protein, calcium, phosphorus, alkaline phosphatase and creatinine, $24 \mathrm{~h}$ urinary calcium) and some second level tests (TSH, Parathormone, 25-OH-vitamin D, serum protein electrophoresis). These tests are sufficient to exclude $90 \%$ of the secondary causes of osteoporosis. Only the evaluation of these parameters will guarantee that we are giving to the patient appropriate treatment [10].

It is important to make at any age a diagnosis of secondary causes of osteoporosis, such as hyperthyroidism and hyperparathyroidism, because these can now be treated with drugs and not only by surgery $[11,12]$.

\subsubsection{Set Up an Appropriate and Personalised Treatment}

Some studies show that anti-osteoporotic drugs are frequently interrupted within 1 month of their prescription; this happens not so much due to the occurrence of adverse events but mostly because patients have not been sufficiently informed about the importance of taking the drug and because they not receive personalised treatment [13]. 


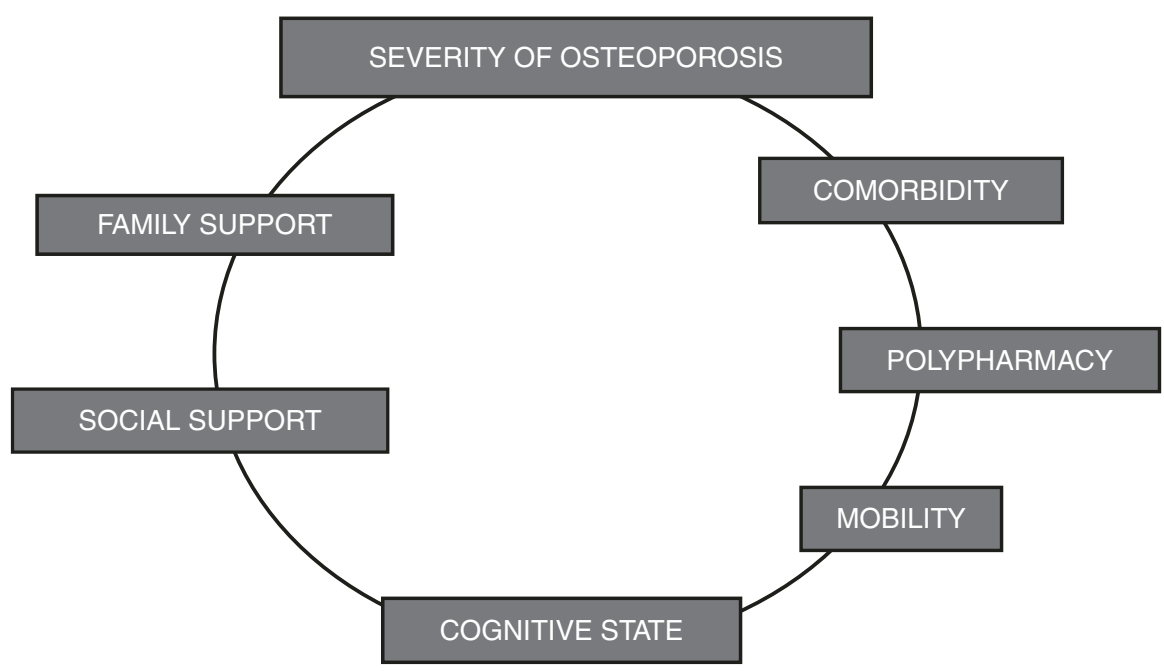

Fig. 15.1 Tailored treatment of osteoporosis in elderly people

The orthogeriatric patient with non-vertebral fracture has specific characteristics: they are normally very old (over 75 years) and present all the characteristics of frailty (reduced mobility, malnutrition, comorbidity, cognitive impairment, polypharmacy, neurosensory deficits). To improve adherence, in addition to osteoporosis severity, the degree of frailty and social family support should be considered in the choice of treatment. Osteoporosis treatment presents many choices [14], both in the route of administration and dosage frequency, so it is possible to define, together with the caregivers, a tailored treatment (Fig. 15.1). For example, subcutaneous or intramuscular administration may be easier or more complicated than oral intake depending on the patient's overall clinical and social conditions.

Sometimes, a drug recommended on the basis of severity of osteoporosis is not the most suitable for the patient. The need to renew the treatment plan every year, for an institutionalised elderly patient with a low family support, can be problematic. Depending on the complexity of the patient, a specialist management of osteoporosis therapy by a bone specialist may be necessary.

Another important point to improve adherence is that, on discharge from the orthopaedic department, the patient should be referred to a Fracture Liaison service that can also follow up the patient and change the medication in the light of the occurrence of new fractures under treatment, BMD measurement, change in clinical or social conditions and so on [15].

\subsection{Non-pharmacological Treatment}

\subsubsection{Lifestyle and Exercise}

Excessive use or abuse of alcohol should be avoided for a number of health-related risks, including bone loss. Moderate drinking during a meal (one glass of wine or beer), or only in social occasions, is harmless. Likewise, caffeine intake is harmful only when 
excessive amounts are ingested, although its calciuric effect should be compensated by increasing calcium intake. On the other hand, any form of nicotine use should be discouraged, although substantial negative effects of cigarette smoking on bone health are seen only in individuals with smoking histories of 30 pack-years or above.

By and large, the most important lifestyle factor to be included in managing patients with osteoporosis is physical activity. The amount and intensity of weightbearing physical activity in young healthy individuals is a determinant of peak bone mass. Likewise, a sedentary lifestyle and prolonged bed rest lead to increased bone loss in the involutional period. Therefore, attempts should be made to encourage physical activity and implement a moderate exercise programme to minimise bone loss in elderly people.

For the older individual with vertebral fractures and severe loss of bone mass, walking may be the only feasible exercise. Swimming, which is an excellent exercise for older individuals to condition muscle tone and strength, does not appear to alter bone loss patterns appreciably because it is not a weight-bearing exercise. Bone mineral content in the spine may be increased somewhat by more vigorous programmes, individualised for target heart-rate ranges, which depend on age and the maximum predicted pulse.

Cessation of exercise results in a gradual but progressive loss of bone. When recommending exercise regimens for elderly women of unknown cardiovascular fitness with established vertebral osteoporosis, patients should be advised about the adverse effects of strenuous exercise. Extension or isometric exercises are more appropriate for these individuals because vertebral compression fractures are more apt to occur during flexion exercise. These aerobic conditioning exercise programmes should be implemented with physician advice and should also include warm-up and cool-down intervals.

\subsection{Pharmacological Interventions}

A wide variety of drugs have been proposed for either preventing bone loss in highrisk populations or preventing fracture and further bone loss in individuals with a previous fracture.

\subsubsection{Ca and Vitamin D to All Patients in Association with Anti-osteoporotic Therapy}

There have been controversies in the literature on the efficacy of calcium and vitamin D for the prevention of osteoporosis and fractures without other drugs. However, in the oldest patients, including orthogeriatric patients, all data confirm that vitamin $\mathrm{D}$ deficiency is very common and calcium intake is often not adequate.

So, osteoporosis guidelines recommend:

- Older people should routinely receive vitamin D supplements [16].

- In postmenopausal women with low BMD and at high risk of fractures, calcium and vitamin D should be used as an adjunct to osteoporosis therapies, otherwise the latter will be ineffective [3]. 
There is broad consensus that vitamin D levels should be maintained above $20 \mathrm{ng} /$ $\mathrm{mL}$; this would already be a good result for orthogeriatric patients, who generally have values lower than $8 \mathrm{ng} / \mathrm{mL}$ [17]. Regarding the recommended dose of vitamin $\mathrm{D}$, local guidelines should be followed; the most widespread programme for the correction of vitamin D deficiency $(<10 \mathrm{ng} / \mathrm{mL})$ consists of cholecalciferol in quite high doses of 50,000 IU per week for 1 or 2 months; then continued daily, weekly or monthly doses that guarantee 1200 IU daily. The most appropriate form of vitamin D to use (cholecalciferol, calcifediol, alfacalcidol, calcitriol) depends on the patient's condition and compliance. However, hydroxylated vitamin D metabolites increase the risk of hypercalcaemia and hypercalciuria; they may therefore need to be ruled out or monitored with serial serum and urinary calcium measurement [18].

It is difficult for older patients to have an adequate calcium intake by diet alone, but it is better to improve the dietary intake before giving a calcium supplementation. Many calcium formulations are available and the most suitable one should be recommended for each patient; for example, calcium carbonate should not be prescribed for patients with dyspepsia or who use protonic pump inhibitors (PPI) - for these patients, formulations of calcium citrate are more suitable [19].

\subsubsection{Choose the Safe and Effective Drug for the Orthogeriatric Patient}

We have many drugs for the treatment of patients at high risk of fracture (see Table 15.1) [14], but we should choose drugs based on efficacy and safety evidence provided by targeted studies or extrapolated data in old age subgroups.

For example, the use of oestrogen, tibolone and selective oestrogen receptor modulators (SERMs) is not recommended in orthogeriatric patients because they do not fit the patient characteristics appropriate for these drugs according to the latest guidelines. Specifically, they are not usually under 60 years of age or $<10$ years past menopause, with low risk of deep vein thrombosis and low cardiovascular risk. Moreover, in most countries these drugs are approved for the prevention but not the treatment of osteoporosis, nor for secondary prevention of fracture [3, 14].

We can divide osteoporosis therapies into two groups: antiresorptive and anabolic.

Table 15.1 Fracture risk reduction and route of administration of antiresorptive drugs

\begin{tabular}{|c|c|c|c|c|c|}
\hline \multirow[b]{2}{*}{$\begin{array}{l}\text { Antiresorptive } \\
\text { drugs }\end{array}$} & \multirow[b]{2}{*}{ Route of administration } & \multicolumn{4}{|c|}{ Fracture risk reduction } \\
\hline & & Vertebral & Hip & $\begin{array}{l}\text { Non- } \\
\text { vertebral }\end{array}$ & Elderly \\
\hline Alendronate & Oral once daily or weekly & Yes & Yes & Yes & Yes \\
\hline Risedronate & Oral once daily, weekly, or monthly & Yes & Yes & Yes & Yes \\
\hline Ibandronate & $\begin{array}{l}\text { Oral once monthly or intravenous } \\
\text { every } 3 \text { months }\end{array}$ & Yes & $\mathrm{ND}^{\mathrm{a}}$ & $\mathrm{ND}^{\mathrm{a}}$ & Yes \\
\hline Zoledronic acid & Intravenous once yearly & Yes & Yes & Yes & Yes \\
\hline Denosumab & $\begin{array}{l}\text { Subcutaneous injection every } \\
6 \text { months }\end{array}$ & Yes & Yes & Yes & Yes \\
\hline
\end{tabular}

aStudies not powered to observe effect on hip or non-vertebral fracture risk 


\subsection{Antiresorptive Therapies}

The fracture risk reduction and route of administration of antiresorptive drugs are shown in Table 15.1.

\subsubsection{Bisphosphonates}

Bisphosphonates are chemically related to inorganic pyrophosphate, which is a potent inhibitor of calcium phosphate crystallisation and dissolution. These compounds act primarily by inhibiting osteoclast-mediated bone resorption via a variety of mechanisms. Small changes in the basic structure of the bisphosphonate can result in extensive alterations in its biological, toxicological and physiochemical characteristics in addition to its therapeutic potential for the treatment of osteoporosis. Of the bisphosphonates that have been synthesised, etidronate, clodronate, ibandronate, zoledronate, alendronate and risedronate have been available commercially for varying periods of time for the treatment osteoporosis. Others, such as neridronate, are currently being tested for use in osteoporosis.

The bisphosphonates are not all the same; their effectiveness, long-term action and safety depend on the strength of their bond with hydroxyapatite (Fig. 15.2); because of this link they have different dosages and ways of administration so it is possible to choose a personalised treatment based on the needs of the patient [20]. Another advantage is the low cost of oral therapy which makes it accessible even to patients with low economic resources.

Clodronate is currently commercially available in a variety of international locations. Clodronate does not inhibit bone mineralisation in doses recommended for osteoporosis therapy.

Fig. 15.2 Kinetic binding affinity of bisphosphonates

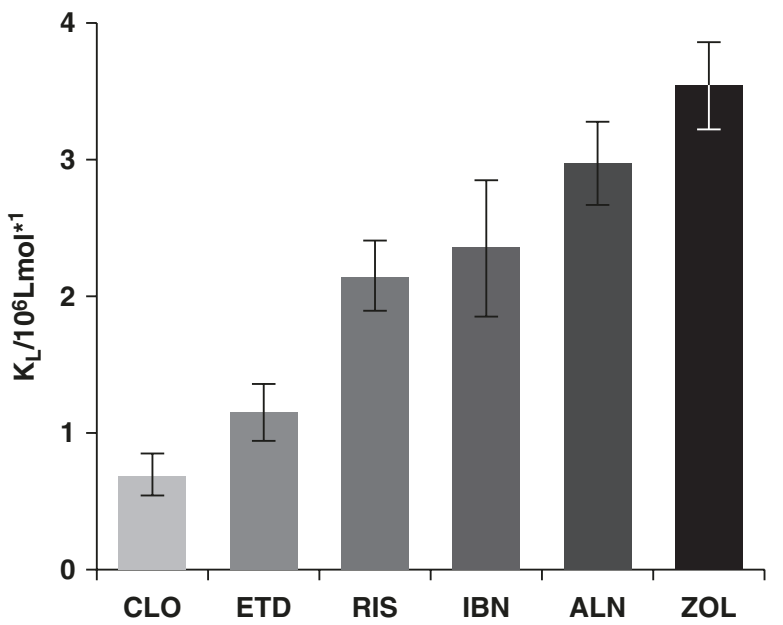


Alendronate was the first bisphosphonate to be approved by the U.S. Food and Drug Administration for the prevention and treatment of postmenopausal and glucocorticoid-induced osteoporosis and osteoporosis in men. Alendronate, an aminobisphosphonate with approximately 700 times more potency than etidronate in inhibiting bone resorption, has been shown in several controlled trials to increase bone density and reduce vertebral and hip fractures among postmenopausal women with low bone density. It also increases bone density in men and women taking glucocorticoids and in men with idiopathic osteoporosis. Data on the effectiveness of alendronate are the largest currently available for any drugs used in osteoporosis treatment.

The Fracture Intervention Trial (FIT) was the first randomised, controlled trial designed with fracture reduction as the primary outcome. In the vertebral fracture arm of FIT, 2027 women with low bone mass and at least one pre-existing vertebral fracture were randomly assigned to receive a placebo or alendronate $5 \mathrm{mg}$ (raised to $10 \mathrm{mg}$ at month 24) daily for 3 years [21]. They were also given $500 \mathrm{mg}$ of calcium and $250 \mathrm{IU}$ of vitamin D. The proportion of women with new morphometrically (radiologically) defined vertebral fracture(s) was 55\% lower in those taking alendronate $(8 \%)$ relative to those taking placebo $(15 \%)$. Likewise, the proportion of women with clinically evident (reported during the study as adverse events) new vertebral fractures was $47 \%$ lower in the alendronate $(2.3 \%)$ relative to the placebo group $(5.0 \%)$. The relative risk for two or more morphometric vertebral fractures was reduced by $\sim 90 \%$ by alendronate treatment, demonstrating that the best results are obtained in subjects at the highest risk. Importantly, the incidence of hip fractures was also reduced to $51 \%$ in women taking alendronate, an extraordinary finding considering the size of the study that was not designed to detect effects on hip fracture, a much less frequent event relative to vertebral fractures [21]. These results remain a milestone observation that has revolutionised the approach to treating osteoporosis and demonstrate the efficacy of this bisphosphonate for fracture prevention.

In the non-vertebral fracture arm of the FIT trial, 4432 postmenopausal women with femoral neck $\mathrm{T}$ score $<-1.6$, but without vertebral fractures at baseline were studied in the same fashion as for the vertebral fracture arm. At the end of the study, there was an overall statistically significant $44 \%$ reduction in new morphometrically defined vertebral fractures in the alendronate group. Although clinical vertebral fractures or hip fractures were not statistically decreased in this study population, in the subgroup of women with femoral neck T-score $<-2.5$ there was indeed a reduction in both clinical vertebral fractures $(36 \%)$ and hip fractures $(56 \%)$ in the alendronate group. This result underscores the concept that, in primary prevention, therapeutic interventions are only effective in subjects at risk. When the risk is low or absent, expecting an effect may be unreasonable. Hence, a diagnosis of osteoporosis or a full estimation of fracture risk should always be made before committing a patient to long-term therapies with a bone active drug.

Risedronate. In early postmenopausal women, $5 \mathrm{mg}$ daily of risedronate for 2 years produced $5.7 \%$ and $5.4 \%$ increments of vertebral and trochanter bone 
density, respectively. Efficacy on vertebral fracture prevention was demonstrated in the VERT (Vertebral Efficacy with Risedronate Therapy) trial, which was conducted on 2458 postmenopausal osteoporotic (femoral neck T-score $<-2.5$ ) women with at least 1 vertebral fracture at baseline, as two separate trials in North America and in the rest of the world [22]. Relative to women receiving only vitamin D (500 IU) and calcium (1000 mg), $5 \mathrm{mg}$ of risedronate daily resulted in significant increases in bone density at the lumbar spine and proximal femur, and reduced the incidence of new vertebral fractures by as much as $65 \%$ within the first year of the study and by $41 \%$ at 3 years [22]. As a secondary outcome, a significant $39 \%$ reduction in nonvertebral fractures among treated women was detected, but no significant reduction in hip fractures was noted. While the VERT trial was not powered to detect such an effect, the HIP (Hip Intervention Program) found a 30\% reduction in new hip fracture in women taking risedronate (pooled data from 2.5 and $5 \mathrm{mg}$ daily) [23]. In addition to the indication for prevention and therapy of postmenopausal osteoporosis, risedronate is also approved for the treatment of steroid-induced osteoporosis.

Ibandronate is a third generation, potent bisphosphonate currently available at $150 \mathrm{mg}$ once a month. Bone markers of turnover were also suppressed, although with a fluctuating pattern.

Zoledronate is the most potent bisphosphonate among the ones currently available in clinical medicine. With intravenous administration, zoledronate at a yearly dose of $5 \mathrm{mg}$ is currently approved for the treatment of osteoporosis, hypercalcemia of malignancy and bone metastases. The Horizon trial [24] demonstrated a $40 \%$ reduction in zoledronate-treated patients versus placebo for hip fractures, rising to more than $50 \%$ for vertebral fractures. Zoledronate treatment is also associated with $30 \%$ reduction in mortality. Recent data [25] have shown also a strong efficacy of zoledronate used every 18 months for 5 years in osteopenic post-menopausal women. Importantly, secondary analysis also proved efficacy for reducing the risk of cardiovascular diseases and mortality.

Use of zoledronate is limited by hospital setting and acute reaction symptoms.

\subsubsection{Adverse Events}

The common ones are upper gastrointestinal adverse reactions with oral dosing, acute phase reaction with intravenous dosing. The uncommon are bone, joint and muscle pain.

The rare ones are eye inflammation, femoral shaft or subtrochanteric fractures with atypical radiographic features, osteonecrosis of the jaw.

In recent years, the fear of rare side effects of bisphosphonates has increased, in particular, osteonecrosis of the jaw, an opportunistic infection with actinomyces caused by the inhibition of osteoclast activity that mostly happens after dental surgery. It is appropriate to recall the Joint Position of ASBMR which reiterates that the incidence of this event is only 1:100,000 in patients who are treated with bisphosphonates for osteoporosis while it is much higher in patients treated for bone metastases or immunosuppressed. It is however recommended to perform a dental check before starting therapy and always maintaining good oral hygiene. 
Contraindications for all these drugs are hypersensitivity and hypocalcaemia. For oral drugs: oesophageal abnormalities that delay emptying, inability to remain upright; zoledronic acid should not be used in impaired renal function (creatinine clearance less than $35 \mathrm{~mL} / \mathrm{min}$ ).

There is a warning about the use of bisphosphonates in patients with severe renal impairment.

\subsubsection{Technical Remark}

Since their chemical structure is acidic, bisphosphonates are irritant for the oesophageal mucosa if contact is prolonged. This problem can be overcome by taking the drug with 100-200 $\mathrm{mL}$ of water while standing upright for 30-40 min.

An important technical remark about in patients who are taking bisphosphonates is that fracture risk be reassessed after $3-5$ years:

- If the risk is still high: the patient should continue therapy.

- If the risk has become low-moderate: the patient should be considered for a temporary discontinuation of bisphosphonates (bisphosphonate holiday).

A bisphosphonate holiday should involve a reassessment of fracture risk at 2-4 year intervals and consideration of reinitiating osteoporosis therapy earlier than 5 years if there is a significant decline in BMD, a new fracture or certain other factors [3].

\subsubsection{Rank Ligand Inhibitor}

Denosumab is a human monoclonal antibody that specifically targets RANK Ligand, an essential mediator of osteoclast formation, function and survival. The binding of this drug to RANK ligand prevents the activation of RANK on the surface of osteoclasts and their precursors. Prevention of the RANKL/RANK interaction inhibits osteoclast formation, function and survival, thereby decreasing bone resorption and increasing bone mass and strength in both cortical and trabecular bone [26]. This drug therefore has a completely different mechanism of action from that of bisphosphonates and does not bind to bone, which is why it was more effective than bisphosphonates in the prevention of non-vertebral fractures. The effects of Denosumab on bone remodelling, reflected in bone turnover markers, reverse after 6 months [27] so it can administered only twice per year (see Table 15.2).

The positive effects of Denosumab treatment on BMD persist for 10 years (Freedom) and there is no increase in adverse effects [28]. Denosumab advantages for hip fracture patients are that it can be administered during hospitalisation in bedridden patients and doesn't have a toxicity risk in patients affected by hepatic or renal chronic failure (even with dialysis) [29]. In countries where its prescription needs a bone specialist management, family or social support is necessary. 
Table 15.2 Fracture risk and route of administration of anabolic drugs

\begin{tabular}{|c|c|c|c|c|c|}
\hline \multirow[b]{2}{*}{ Anabolic drugs } & \multirow[b]{2}{*}{ Route of administration } & \multicolumn{4}{|c|}{ Fracture risk reduction } \\
\hline & & Vertebral & Hip & $\begin{array}{l}\text { Non- } \\
\text { vertebral }\end{array}$ & Elderly \\
\hline Teriparatide & $\begin{array}{l}\text { Subcutaneous injection } \\
\text { daily for } 2 \text { years }\end{array}$ & Yes & $\mathrm{ND}^{\mathrm{a}}$ & Yes & Yes \\
\hline $\begin{array}{l}\text { Abaloparatide (not } \\
\text { available in Europe) }\end{array}$ & $\begin{array}{l}\text { Subcutaneous injection } \\
\text { daily for } 2 \text { years }\end{array}$ & Yes & $\mathrm{ND}^{\mathrm{a}}$ & Yes & Yes \\
\hline Romosozumab & $\begin{array}{l}\text { Subcutaneous injection } \\
\text { monthly for } 1 \text { years }\end{array}$ & Yes & Yes $^{\mathrm{b}}$ & Yes & Yes \\
\hline
\end{tabular}

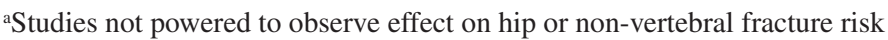

${ }^{b}$ Data available only in sequential therapy with alendronate

\subsubsection{Adverse Events}

Uncommon: skin rash; rare: cellulitis, femoral shaft or subtrochanteric fractures with atypical radiographic features, osteonecrosis of the jaw.

Contraindications for Denosumab use are hypocalcaemia, pregnancy, hypersensitivity;

Warning: multiple vertebral fractures have occurred when Denosumab has been discontinued.

\subsubsection{Technical Remark}

A drug holiday is not recommended with Denosumab, administration should be not delay or stopped without subsequent antiresorptive therapy to prevent a rebound in bone turnover [30].

\subsection{Anabolic Drugs}

Anabolic drugs are recommended in postmenopausal women at very high risk of fracture, such as those with severe or multiple fractures. Osteoanabolic therapy has the potential to restore skeletal microstructure and uniquely transform osteoporotic bone towards normal [31]. We have two class of anabolic drugs: parathyroid hormone receptor agonist and sclerostin antibody (see Table 15.3). Teriparatide is a current therapy, whereas abaloparatide and romosozumab should be considered emerging therapies.

The fracture risk reduction and the route of administration of anabolic drugs are shown in Table 15.2.

\subsubsection{Parathyroid Hormone Receptor (PTHr) Agonists: Teriparatide and Abaloparatide}

The safety and efficacy of PTHr agonists have not been established beyond 2 years of treatment so the maximum duration of therapy over a patient's lifetime is 24 months. 
Table 15.3 Fundamental recommendation in secondary prevention in the elderly (modified by the American Society of Bone and Mineral Research Secondary prevention Guidelines 2019)

- Offer pharmacologic therapy for osteoporosis to people aged 65 years or older with a hip or vertebral fracture, to reduce their risk of additional fractures

- Do not delay initiation of therapy for bone mineral density (BMD) testing

- Consider patients' oral health before starting therapy with bisphosphonates or denosumab

- For patients who have had repair of a hip fracture or are hospitalized for a vertebral fracture:

Oral pharmacologic therapy can begin in the hospital and be included in discharge orders Intravenous and subcutaneous pharmacologic agents may be therapeutic options after the first 2 weeks of the postoperative period. Concerns during this early recovery period include:

Hypocalcemia because of factors including vitamin D deficiency or perioperative overhydration

Acute phase reaction of flu-like symptoms following zoledronic acid infusion, particularly in patients who have not previously taken zoledronic acid or other bisphosphonates

If pharmacologic therapy is not provided during hospitalization, then mechanisms should be in place to ensure timely follow-up.

- Initiate a daily supplement of at least $800 \mathrm{IU}$ vitamin D per day for people aged 65 years or older with a hip or vertebral fracture.

- Initiate a daily calcium supplement for people aged 65 years or older with a hip or vertebral fracture who are unable to achieve an intake of $1200 \mathrm{mg} /$ day of calcium from food sources.

- Because osteoporosis is a life-long chronic condition, routinely follow and re-evaluate people aged 65 years or older with a hip or vertebral fracture who are being treated for osteoporosis. Purposes include:

- Reinforcing key messages about osteoporosis and associated fractures

- Identifying any barriers to treatment plan adherence that arise

- Assessing the risk of falling

- Monitoring for adverse treatment effects

- Evaluating the effectiveness of the treatment plan; and

- Determining whether any changes in treatment should be made, including whether any antiosteoporosis pharmacotherapy should be changed or discontinued

In the registration study the hip fracture reduction for both agents was not statistically significant, probably because the numbers of hip fracture were small and the studies were inadequately powered for this endpoint; however, increased bone strength in the hip has been reported with longer term treatment [32].

These agents are much more expensive than other antiosteoporotic drugs, for this reason, they are used only in secondary treatment.

Teriparatide is a fragment of full-length PTH, it is recommended for postmenopausal women with osteoporosis at very high risk of fracture (severe or multiple fractures) [33].

In comparator studies, teriparatide was significantly more effective in:

- Protecting postmenopausal women with osteoporosis from vertebral fracture than was risedronate [34].

- Preventing new vertebral fractures in glucocorticoid-induced osteoporosis than was alendronate [35].

Its use is limited to 24 months due to a significant increase in osteosarcoma in rats given the drug for longer than this period but, since the introduction of 
teriparatide in 2002, in more than 1 million patients the rate of osteosarcoma has not been greater than expected [36].

Abaloparatide is a PTH-related protein analogue (PTHrP). It has a mechanism of action similar to teriparatide, but it showed a little more efficacy in preventing vertebral fractures compared with placebo, and milder adverse events than teriparatide [37].

Abaloparatide is not available in Europe because EMA refused its commercialisation on grounds of doubts about its effectiveness in reducing non-vertebral fractures and a tendency to tachycardia and palpitations.

\subsubsection{Adverse Events}

Common: nausea, dizziness, muscle cramps, increased serum or urine calcium or serum uric acid; uncommon: orthostatic hypotension. Abaloparatide causes less hypercalcemia but causes palpitations [38].

Contraindications: Hypercalcemia, hypersensitivity, nephrolithiasis.

Warnings: should not be used in children or adolescents with open epiphyses, or patients with Paget's disease of bone, previous external beam or implant radiation involving the skeleton, bone metastases, history of skeletal malignancies, other metabolic bone diseases or hypercalcaemic disorders.

\subsubsection{Anti-Sclerostin Antibody: Romosozumab}

Romosozumab is a monoclonal antibody that binds and inhibits sclerostin. It exerts a dual effect on bone: increased bone formation and decreased bone resorption [39]. During 2019 it was approved by FDA and EMA and in Japan for the treatment of osteoporosis in postmenopausal women at high risk of fracture.

The sequence of Romosozumab followed by an antiresorptive therapy may provide significant benefits for the treatment of osteoporosis in women at high risk for fracture [40].

Another study demonstrated that 1 year of Romosozumab followed by 1 year of Denosumab treatment in the FRAME trial led to BMD changes similar to 7 years of Denosumab treatment [41]. An increased risk of cardiovascular events was observed compared with alendronate but not compared with placebo.

\subsubsection{Adverse Events}

Common: Injection-site reaction (pain (1.6\% of patients), erythema (1.3\%), pruritus $(0.8 \%)$, haemorrhage $(0.5 \%)$, rash $(0.4 \%)$ and swelling $(0.3 \%)$.

Contraindications: hypersensitivity.

\subsubsection{Technical Remark for Anabolic Agents}

In patients who have completed a course of anabolic agents, it is recommended to switch to treatment with antiresorptive therapies, to maintain bone density gains [3]. 


\subsection{Influence of Osteoporosis Medication on Fracture Healing}

Pharmacologic agents that influence bone remodelling are an essential component of osteoporosis management. Because many patients are first diagnosed with osteoporosis when presenting with a fragility fracture, it is critical to understand how osteoporotic medications influence fracture healing. Vitamin D and its analogues are essential for the mineralisation of the callus and may also play a role in callus formation and remodelling that enhances biomechanical strength. In animal models, antiresorptive medications, including bisphosphonates, denosumab, calcitonin, oestrogen and raloxifene, do not impede endochondral fracture healing but may delay remodelling. Although bisphosphonates and denosumab delay callus remodelling, they increase callus volume and result in unaltered biomechanical properties. Parathyroid hormone, an anabolic agent, has demonstrated promise in animal models, resulting in accelerated healing with increased callus volume and density, more rapid remodelling to mature bone and improved biomechanical properties. Clinical data with parathyroid hormone have demonstrated enhanced healing in distal radius and pelvic fractures as well as postoperatively following spine surgery [42].

There is currently no evidence that osteoporosis treatments are detrimental for bone repair and some promising experimental evidence for positive effects on healing, notably for agents with a bone-forming mode of action, which may translate into therapeutic applications [43].

\subsection{Conclusion}

There is a range of good pharmacological options and indications for sequential therapy to reduce the risk of further fracture in orthogeriatric patients; despite this they are frequently undertreated. The literature shows that treatment can be started even in very old patients at high risk of fracture and may be continued for as long as the developing evidence shows efficacy and safety.

Undertreatment of patients following hip fracture is an important age-related health disparity that must be addressed by both health systems and individual clinicians. The challenge for the multidisciplinary approach to fracture patients is to abolish undertreatment, thereby enabling a real improvement of quality of life for our patients.

New guidelines on secondary fracture prevention have been recently released by an international coalition led by the American Society of Bone and Mineral Research and should be followed by treating physicians and health care providers [44] (see Table 15.3).

\section{References}

1. Lonnroos E, Kautiainen H, Karppi P, Hartikainen S, Kiviranta I, Sulkava R (2007) Incidence of second hip fractures. A population-based study. Osteoporos Int 18(9):1279-1285

2. Pioli G, Barone A, Mussi C, Tafaro L, Bellelli G, Falaschi P, Trabucchi M, Paolisso G (2014) GIOG: The management of hip fracture in the older population. Joint position statement by Gruppo Italiano Ortogeriatria (GIOG). Aging Clin Exp Res 26(5):547-553 
3. Eastell R, Rosen CJ, Black DM, Cheung AM, Murad MH, Shoback D (2019) Pharmacological management of osteoporosis in postmenopausal women: an endocrine Society Clinical practice guideline. J Clin Endocrinol Metab 104(5):1595-1622

4. Eisman JA, Bogoch ER, Dell R, Harrington JT, McKinney RE Jr, McLellan A, Mitchell PJ, Silverman S, Singleton R, Siris E (2012) Making the first fracture the last fracture: ASBMR task force report on secondary fracture prevention. J Bone Miner Res 27(10):2039-2046

5. Orimo H, Nakamura T, Hosoi T, Iki M, Uenishi K, Endo N, Ohta H, Shiraki M, Sugimoto T, Suzuki T, Soen S, Nishizawa Y, Hagino H, Fukunaga M, Fujiwara S (2012) Japanese 2011 guidelines for prevention and treatment of osteoporosis--executive summary. Arch Osteoporos 7:3-20

6. Schuit SC, van der Klift M, Weel AE et al (2004) Fracture incidence and association with bone mineral density in elderly men and women: the Rotterdam Study. Bone 34:195-202

7. Wong TC, Wu WC, Cheng HS, Cheng YC, Yam SK (2007) Spontaneous fractures in nursing home residents. Hong Kong Med J 13(6):427-429

8. Crilly RG, Hillier LM, Mason M, Gutmanis I, Cox L (2010) Prevention of hip fractures in long-term care: relevance of community-derived data. J Am Geriatr Soc 58(4):738-745

9. Kaga Y, Ishii S, Kuroda I, Kamiya Y, Nakamura K, Kanemura H, Sugita K, Aihara M (2017) The efficacy of intravenous alendronate for osteoporosis in patients with severe motor intellectual disabilities. No To Hattatsu 49(2):113-119

10. Kanis JA, Burlet N, Cooper C, Delmas PD, Reginster JY, Borgstrom F et al (2008) European guidance for the diagnosis and management of osteoporosis in postmenopausal women. Osteoporos Int 19(4):399-428

11. Khan AA et al (2017) Primary hyperparathyroidism: review and recommendations on evaluation, diagnosis, and management. A Canadian and international consensus. Osteoporos Int 28(1):1-19

12. Compston JE, McClung MR, Laslie WD (2019) Osteoporosis. Lancet 393:364-376

13. Tafaro L, Nati G, Leoni E, Baldini R, Cattaruzza MS, Mei M, Falaschi P (2013) Adherence to anti-osteoporotic therapies: role and determinants of "spot therapy". Osteoporos Int 24(8):2319-2323

14. Compston JE, McClung MR, Leslie WD (2019) Osteoporosis. Lancet 393(10169):364-376

15. Walters S, Khan T, Ong T, Sahota O (2017) Fracture liaison services: improving outcomes for patients with osteoporosis. Clin Interv Aging 12:117-127

16. Lips P, Cashman K, Lamberg-Allardt C, Bischoff-Ferrari H, Obermayer-Pietsch B, Bianchi M, Stepan J, El-Hajj Fuleihan G, Bouillon R (2019) Current vitamin D status in European and Middle East countries and strategies to prevent vitamin D deficiency: a position statement of the European Calcified Tissue Society. Eur J Endocrinol 180:23-54

17. Giordano S, Proietti A, Bisaccia T, Caso P, Martocchia A, Falaschi P, Tafaro L (2018) Hypovitaminosis D: comparison between patients with hip fracture and patients with vertebral fractures. Osteoporos Int 29(9):2087-2091

18. Nuti R, Brandi ML, Checchia G, Di Munno O, Dominguez L, Falaschi P, Fiore CE, Iolascon G, Maggi S, Michieli R, Migliaccio S, Minisola S, Rossini M, Sessa G, Tarantino U, Toselli A, Isaia GC (2019) Guidelines for the management of osteoporosis and fragility fractures. Intern Emerg Med 14(1):85-102

19. Bauer DC (2014) Calcium supplements and fracture prevention. N Engl J Med 370(4):387-388

20. Russell RG, Xia Z, Dunford JE, Oppermann U, Kwaasi A, Hulley PA, Kavanagh KL, Triffitt JT, Lundy MW, Phipps RJ, Barnett BL, Coxon FP, Rogers MJ, Watts NB, Ebetino FH (2007) Bisphosphonates: an update on mechanisms of action and how these relate to clinical efficacy. Ann N Y Acad Sci 1117:209-257

21. Black DM, Cummings SR, Karpf DB, Cauley JA, Thompson DE, Nevitt MC, Bauer DC, Genant HK, Haskell WL, Marcus R, Ott SM, Torner JC, Quandt SA, Reiss TF, Ensrud KE (1996) Randomised trial of effect of alendronate on risk of fracture in women with existing vertebral fractures. Fracture Intervention Trial Research Group. Lancet 348(9041):1535-1541 
22. Harris ST, Watts NB, Genant HK, CD MK, Hangartner T, Keller M, Chesnut CH 3rd, Brown J, Eriksen EF, Hoseyni MS, Axelrod DW, Miller PD (1999) Effects of risedronate treatment on vertebral and nonvertebral fractures in women with postmenopausal osteoporosis: a randomized controlled trial. Vertebral Efficacy With Risedronate Therapy (VERT) Study Group. JAMA 282(14):1344-1352

23. MR MC, Geusens P, Miller PD, Zippel H, Bensen WG, Roux C, Adami S, Fogelman I, Diamond T, Eastell R, Meunier PJ, Reginster JY, Hip Intervention Program Study Group (2001) Effect of risedronate on the risk of hip fracture in elderly women. Hip Intervention Program Study Group. N Engl J Med 344(5):333-340

24. Black DM, Delmas PD, Eastell R, Reid IR, Boonen S, Cauley JA, Cosman F, Lakatos P, Leung PC, Man Z, Mautalen C, Mesenbrink P, Hu H, Caminis J, Tong K, Rosario-Jansen T, Krasnow J, Hue TF, Sellmeyer D, Eriksen EF, Cummings SR, HORIZON Pivotal Fracture Trial (2007) Once-yearly zoledronic acid for treatment of postmenopausal osteoporosis. N Engl J Med 356(18):1809-1822

25. Reid IR, Horne AM, Mihov B, Stewart A, Garratt E, Wong S, Wiessing KR, Bolland MJ, Bastin S, Gamble GD (2018) Fracture prevention with zoledronate in older women with osteopenia. N Engl J Med 379(25):2407-2416

26. Cummings SR, San Martin J, McClung MR et al (2009) Denosumab for prevention of fractures in postmenopausal women with osteoporosis. N Engl J Med 361:756-765

27. McClung MR, Boonen S, Törring O, Roux C, Rizzoli R, Bone HG, Benhamou CL, Lems WF, Minisola S, Halse J, Hoeck HC, Eastell R, Wang A, Siddhanti S, Cummings SR (2012) Effect of denosumab treatment on the risk of fractures in subgroups of women with postmenopausal osteoporosis. J Bone Miner Res 27(1):211-218

28. Bone HG, Wagman RB, Brandi ML et al (2017) 10 years of denosumab treatment in postmenopausal women with osteoporosis: results from the phase 3 randomised FREEDOM trial and open-label extension. Lancet Diabetes Endocrinol 5:513-523

29. Chen CL, Chen NC, Liang HL, Hsu CY, Chou KJ, Fang HC, Lee PT (2015) Effects of denosumab and calcitriol on severe secondary hyperparathyroidism in dialysis patients with low bone mass. J Clin Endocrinol Metab 100(7):2784-2792

30. Cummings SR, Ferrari S, Eastell R et al (2018) Vertebral fractures after discontinuation of denosumab: a post hoc analysis of the randomized placebo-controlled FREEDOM trial and its extension. J Bone Miner Res 33:190-198

31. Dempster DW, Zhou H, Ruff VA, Melby TE, Alam J, Taylor KA (2018) Longitudinal effects of teriparatide or zoledronic acid on bone modeling- and remodeling-based formation in the SHOTZ Study. J Bone Miner Res 33:627-633

32. Black DM, Greenspan SL, Ensrud KE et al (2003) The effects of parathyroid hormone and alendronate alone or in combination in postmenopausal osteoporosis. N Engl J Med 349:1207-1215

33. Macdonald HM, Nishiyama KK, Hanley DA, Boyd SK (2011) Changes in trabecular and cortical bone microarchitecture at peripheral sites associated with 18 months of teriparatide therapy in postmenopausal women with osteoporosis. Osteoporos Int 22:357-362

34. Kendler DL, Marin F, Zerbini CAF, Russo LA, Greenspan SL, Zikan V, Bagur A, MaloufSierra J, Lakatos P, Fahrleitner-Pammer A, Lespessailles E, Minisola S, Body JJ, Geusens P, Moricke R, Lopez-Romero P (2018) Effects of teriparatide and risedronate on new fractures in post-menopausal women with severe osteoporosis (VERO): a multicentre, double-blind, doubledummy, randomised controlled trial. Lancet 391(10117):230-240

35. Saag KG, Zanchetta JR, Devogelaer JP et al (2009) Effects of teriparatide versus alendronate for treating glucocorticoid-induced osteoporosis: thirty six month results of a randomized, double-blind, controlled trial. Arthritis Rheum 60:3346-3355

36. Black DM, Rosen CJ (2016) Postmenopausal osteoporosis. N Engl J Med 374(3):254-262

37. Miller PD, Hattersley G, Riis BJ et al (2016) Effect of abaloparatide vs placebo on new vertebral fractures in postmenopausal women with osteoporosis: a randomized clinical trial. JAMA 316:722-733 
38. Barrionuevo P, Kapoor E, Asi N, Alahdab F, Mohammed K, Benkhadra K, Almasri J, Farah W, Sarigianni M, Muthusamy K, Al Nofal A, Haydour Q, Wang Z, Murad MH (2019) Efficacy of pharmacological therapies for the prevention of fractures in postmenopausal women: a network meta-analysis. J Clin Endocrinol Metab 104(5):1623-1630

39. Cosman F, Crittenden DB, Adachi JD et al (2016) Romosozumab treatment in postmenopausal women with osteoporosis. N Engl J Med 375:1532-1543

40. Saag K, Petersen J, Brandi M, Karaplis A, Lorentzon M, Thomas T, Maddox J, Fan M, Meisner P, Grauer A (2017) Romosozumab or alendronate for fracture prevention inwomen with osteoporosis. N Engl J Med 377:1417-1427

41. Cosman F, Crittenden DB, Ferrari S, Khan A, Lane NE, Lippuner K, Matsumoto T, Milmont CE, Libanati C, Grauer A (2018) FRAME study: the foundation effect of building bone with 1 year of romosozumab leads to continued lower fracture risk after transition to denosumab. $\mathrm{J}$ Bone Miner Res 33(7):1219-1226

42. Hegde V, Jo JE, Andreopoulou P, Lane JM (2016) Effect of osteoporosis medications on fracture healing. Osteoporos Int 27(3):861-871

43. Goldhahn J, Féron JM, Kanis J, Papapoulos S, Reginster JY, Rizzoli R, Dere W, Mitlak B, Tsouderos Y, Boonen S (2012) Implications for fracture healing of current and new osteoporosis treatments: an ESCEO consensus paper. Calcif Tissue Int 90(5):343-353. https://doi. org/10.1007/s00223-012-9587-4

44. Conley RB, Adib G, Adler RA, Åkesson KE, Alexander IM, Amenta KC, Blank RD, Brox WT, Carmody EE, Chapman-Novakofski K, Clarke BL, Cody KM, Cooper C, Crandall CJ, Dirschl DR, Eagen TJ, Elderkin AL, Fujita M, Greenspan SL, Halbout P, Hochberg MC, Javaid M, Jeray KJ, Kearns AE, King T, Koinis TF, Koontz JS, Kužma M, Lindsey C, Lorentzon M, Lyritis GP, Michaud LB, Miciano A, Morin SN, Mujahid N, Napoli N, Olenginski TP, Puzas JE, Rizou S, Rosen CJ, Saag K, Thompson E, Tosi LL, Tracer H, Khosla S, Kiel DP (2019) Secondary fracture prevention: consensus clinical recommendations from a multistakeholder coalition. J Bone Miner Res. https://doi.org/10.1002/jbmr.3877

Open Access This book is licensed under the terms of the Creative Commons AttributionNonCommercial-NoDerivatives 4.0 International License (http://creativecommons.org/licenses/ by-nc-nd/4.0/), which permits any noncommercial use, sharing, distribution and reproduction in any medium or format, as long as you give appropriate credit to the original author(s) and the source, provide a link to the Creative Commons license and indicate if you modified the licensed material. You do not have permission under this license to share adapted material derived from this book or parts of it.

The images or other third party material in this book are included in the book's Creative Commons license, unless indicated otherwise in a credit line to the material. If material is not included in the book's Creative Commons license and your intended use is not permitted by statutory regulation or exceeds the permitted use, you will need to obtain permission directly from the copyright holder.

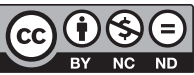

